\title{
Techniek met zorg: kwantiteit en kwaliteit van zorgtechnologische opleidingen
}

T. Sminia, F.B.M. Sanders, A.W. de Weerd, P.A. Wieringa, D.C. Duchatteau, L.J. Schmit Jongbloed, M.C. Willemsen, J.C.C. Borleffs

\section{Samenvatting}

Inleiding: De vraag naar professionals met kennis en vaardigheden op het gebied van technologie en zorg (TZ-professionals) groeit. Niet alleen intramuraal, maar ook extramuraal. Zowel hbo-als wo-instellingen zijn daarom de laatste jaren gestart met nieuwe opleidingen en afstudeerrichtingen die een combinatie van technologie en zorg aanbieden (TZ-opleidingen).

Werkwijze: Een commissie, ingesteld door de minister van Volksgezondheid, Welzijn en Sport, heeft een schatting gemaakt van de te verwachten behoefte aan TZ-professionals op mbo-, hbo- en wo-niveau op de middellange termijn (2020). Deze behoefte is vergeleken met het aantal studenten dat de komende jaren uitstroomt uit de nieuwe TZ-opleidingen en -afstudeerrichtingen.

Resultaten: De opleidingscapaciteit van de nieuwe TZ-opleidingen en -afstudeerrichtingen binnen het hbo en wo is groot genoeg om aan de te verwachten vraag te voldoen. Bovendien kan de opleidingscapaciteit desgewenst snel worden uitgebreid. De kerncompetentie van TZprofessionals is een brede en diepe kennis van de technologie, waarmee zij een duidelijke meerwaarde hebben in een team met andere zorgverleners.

Conclusie en belangrijkste aanbevelingen: De vraag naar medisch-technologische expertise neemt toe, maar op dit moment worden voldoende studenten opgeleid om aan de behoefte op middellange termijn te voldoen. TZ-professionals zullen een belangrijke rol vervullen als bruggenbouwers tussen de twee tot nog toe gescheiden werelden van techniek en zorg. TZ-opleidingen dienen in hun curriculum in de eerste plaats aandacht te geven aan de technologie. In aanvulling daarop moeten zij zorgen voor goede communicatieve vaardigheden en voldoende kennis van de inhoud, organisatie en cultuur van de zorg. De commissie denkt daarbij aan een verdeling van ongeveer $80 \%$ technologische en $20 \%$ medische kennis en vaardigheden. Om voldoende studenten te blijven interesseren voor een TZ-opleiding of -afstudeervariant adviseert de commissie verder dat opleiders inzicht geven in de verschillen en overeenkomsten tussen de diverse TZ-opleidingen en afstudeervarianten; dat opleiders en werkgevers in gezamenlijk overleg duidelijkheid verschaffen over het beroepsbeeld van TZprofessionals; en tenslotte dat opleiders de doorstroommogelijkheden binnen en tussen opleidingen op mbo-, hbo- en wo-niveau beter benutten. (Sminia T, Sanders FBM, Weerd AW de, Wieringa PA, Duchatteau DC, Schmit Jongbloed LJ, Willemsen MC, Borleffs JCC. Techniek met zorg: kwantiteit en kwaliteit van zorgtechnologische opleidingen. Tijdschrift voor Medisch Onderwijs 2005;24(1):35-43.)

\section{Inleiding}

De vraag naar zorgtechnologie neemt toe en dus ook de vraag naar professionals met kennis en vaardigheden op het gebied van technologie en zorg (TZ-professio- nals). De laatste jaren zijn er dan ook verschillende nieuwe hbo- en wo-opleidingen en -afstudeervarianten gestart, die zowel technologie als zorg aanbieden (TZ-opleidingen). Om inzicht te krijgen in de ont- 
wikkeling van deze nieuwe TZ-opleidingen in relatie tot de behoefte aan TZ-professionals heeft de minister van Volksgezondheid, Welzijn en Sport in 2003 de commissie Technologie, Zorg en Opleiding (TZO) ingesteld. De commissie TZO heeft 3 november jl. het rapport aangeboden aan de ministeries van Volksgezondheid, Welzijn en Sport (VWS) en Onderwijs, Cultuur en Wetenschappen (OCW) en aan belanghebbende partijen in het veld. Dit artikel beschrijft de belangrijkste bevindingen en aanbevelingen; het volledige rapport kan worden gedownload via de website van het ministerie van VWS (www.minvws.nl) of worden besteld via www.lsjmp.nl.

\section{Werkwijze}

De commissie TZO heeft gekozen voor een interactieve aanpak met betrokkenen en deskundigen in het veld. Het adviesbureau Smets en Hover heeft onderzoek gedaan naar de vraag op de arbeidsmarkt naar TZ-professionals (dit onderzoeksrapport kan worden gedownload via www.smetshover.nl.). De commissie is als volgt te werk gegaan:

- Verwerven van informatie door literatuurstudie en gesprekken met alle veldpartijen.

- Vormen van een mening binnen de commissie.

- Toetsen van die mening bij het beroepenveld, patiëntenorganisaties, opleiders en beleidsmakers en tegelijkertijd stimuleren van de discussie in het veld. Hiervoor heeft de commissie een invitational conference gehouden en commentaar op het conceptrapport aan het veld gevraagd.

- Actieve verspreiding van de eindresultaten en adviezen voor implementatie.

De opleidingen die de commissie onder de loep heeft genomen, bevinden zich op 'het grensvlak van technologie en zorg' (TZ).
De commissie verstaat onder TZ-opleidingen: opleidingen die een combinatie van technologie en zorg aanbieden, en onder TZ-professionals: professionals die hun technologische kennis en vaardigheden op het gebied van diagnostiek, behandeling en/of R\&D inzetten ten behoeve van de zorg. De commissie heeft zich vooral gericht op TZ-opleidingen en -afstudeervarianten die relatief nieuw zijn, zoals gezondheidszorgtechnologie (hbo) en klinische technologie (wo). Opleidingen en professionals die zich al sinds jaar en dag in de zorg bewezen hebben, zoals audiciens, medisch analisten (mbo) en radiodiagnostisch laboranten (hbo) worden in het rapport beknopt besproken. De medische specialismen met een belangrijke technologische invalshoek vallen buiten de beschouwing van het rapport, omdat de behoefteraming hiervan tot het werkterrein van het Capaciteitsorgaan behoort.

\section{Resultaten}

\section{Welke ontwikkelingen veroorzaken de toenemende vraag naar zorgtechnologie?}

De vraag naar zorgtechnologie groeit en dus ook de vraag naar TZ-professionals. Niet alleen intramuraal, maar in toenemende mate ook extramuraal. Verschillende ontwikkelingen in de maatschappij, zorg, technologie en onderwijs zijn daar de oorzaak van. De belangrijkste zijn wel de vergrijzing, de toenemende behoefte aan thuiszorg en daarmee ook aan thuiszorgtechnologie, de eisen die overheid en consumenten stellen (denk bijvoorbeeld aan een defibrillator in de sporthal) en de nieuwe technische mogelijkheden die elkaar in rap tempo opvolgen. Relevante technische ontwikkelingen voor de zorg zijn: computergerelateerde technologie, moleculaire biologie, thuiszorg- en zelfzorgtechnologie, transplantatiegenees- 
kunde, sensortechnologie, (bio)robotica en tissue engineering. Nieuwe technologieën vinden vaak snel een eerste toepassing in de zorg, maar in vergelijking met een aantal andere landen met een hoogwaardige technologische industrie duurt het in Nederland erg lang (gemiddeld zeventien jaar) voordat een bewezen verbetering algemeen doorgevoerd is. Dit komt onder andere door het huidige budgetsysteem waarbinnen de kosten voor technische innovaties niet of nauwelijks worden gecompenseerd door nieuwe inkomsten. Een andere oorzaak is dat de technische innovatie in de zorg vaak afhankelijk is van individuele artsen die affiniteit met technologie hebben, en minder vaak van het beleid van de organisatie als geheel. De commissie verwacht dat de nieuwe TZ-professionals daar verandering in kunnen en zullen brengen.

\section{Hoe reageert het onderwijs op de toe-} nemende vraag naar zorgtechnologie?

Het hbo en wo reageert sinds een aantal jaren op de toenemende vraag naar zorgtechnologie door nieuwe TZ-opleidingen aan te bieden, zoals gezondheidszorgtechnologie en biometrie (hbo) en klinische technologie en biomedische technologie (wo). Daarnaast bieden sommige bestaande technische opleidingen minors of afstudeerrichtingen aan op het gebied van zorg, waardoor ook een mix van techniek en zorg ontstaat. Zo is 'human care and technology' een afstudeerrichting bij technische opleidingen in het hbo. Deze TZopleidingen zijn een interessant alternatief voor studenten die een 'harde' techniek- of bètastudie niet aantrekkelijk vinden. Er zijn geen nieuwe TZ-opleidingen binnen het mbo ontstaan, omdat men zich daar altijd al bewust is geweest van de verwevenheid tussen theorie en praktijk en het belang van aansluiting op veranderende behoeften in de markt.

\section{Hoeveel TZ-professionals zijn er de komende jaren nodig?}

De commissie TZO vergelijkt de huidige en te verwachten vraag naar nieuwe TZprofessionals met het huidige opleidingsaanbod en schetst een toekomstscenario voor de middellange termijn (2020).

\section{Huidige arbeidsmarkt}

Al decennialang werken duizenden TZprofessionals op mbo-, hbo- en wo-niveau in en buiten de zorg. Maar de schatting van de behoefte aan nieuwe TZ-professionals is niet op deze traditionele beroepsgroepen gebaseerd. De commissie heeft zich vooral gebogen over de behoefte aan de nieuwe TZ-professionals die niet een al langer bestaande opleiding (zoals functielaborant of radiodiagnostisch laborant) gevolgd hebben, maar een andere opleiding zoals 'bacholor of engineering'. Want dát zijn de professionals c.q. de beroepen waarop de nieuwe TZ-opleidingen binnen het hbo en wo zich richten. Op hbo-niveau werken er nu tussen de 425 en 1.170 van dergelijke TZ-professionals en op woniveau (zonder postinitieel vervolgonderwijs) zijn dat er naar schatting tussen de 275 en 645 (zie figuur 1).

\section{Huidig opleidingsaanbod}

Momenteel zijn ongeveer 550 studenten in opleiding bij de nieuwe TZ-opleidingen en afstudeerrichtingen op hbo-niveau. In 2004 hebben zich nog eens 275 studenten voor deze hbo-opleidingen aangemeld. Op wo-niveau schreven zich in 2004 ruim 300 studenten in.

\section{Schatting toekomstige arbeidsmarkt}

De commissie TZO heeft een schatting gemaakt van de behoefte aan TZ-professionals op de middellange termijn (2020) (zie tabel 1). Daarbij zijn een aantal arbitraire maar wel beredeneerde aannames gemaakt over de toename van de 


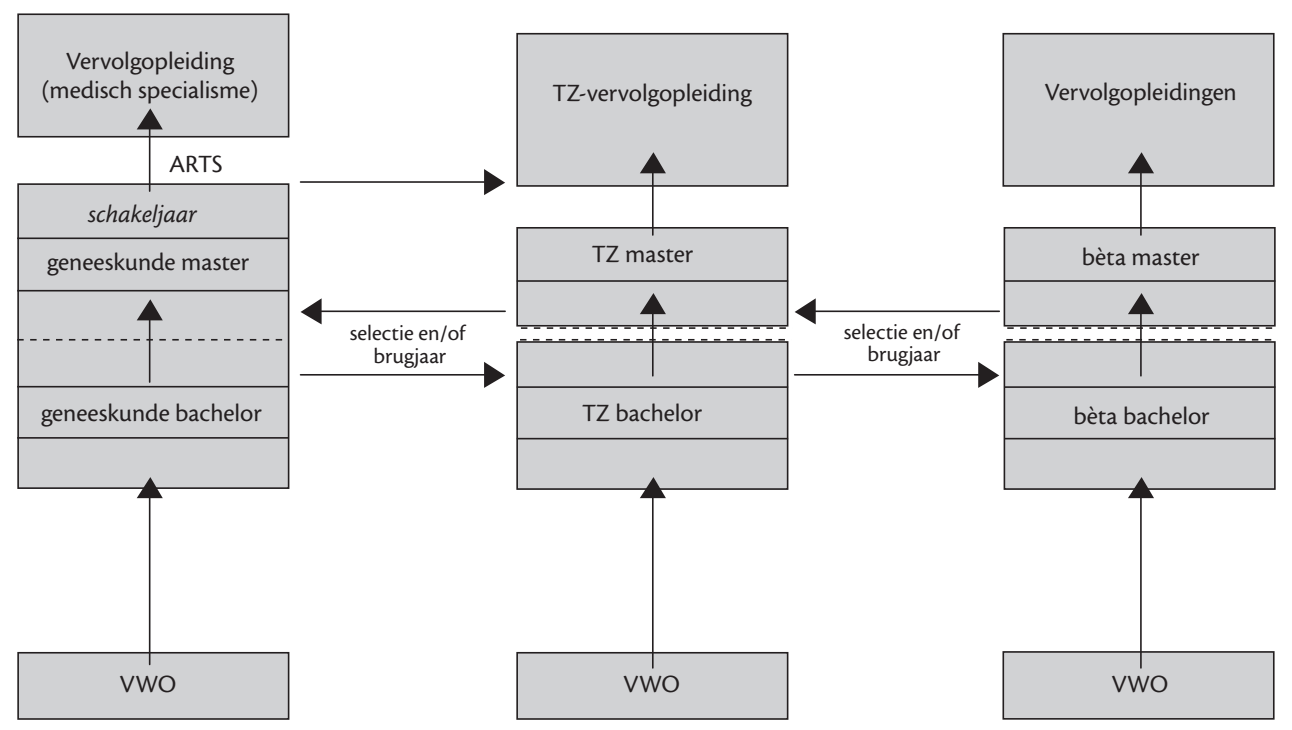

Figuur 1. Flexibiliteit binnen het bachelor/master-model.

zorgvraag (factor 1.5), de verdergaande technologisering (factor 2) en overige ontwikkelingen, zoals taakherschikking, meer aandacht voor veiligheid, artsentekort, etc. (factor 2). Voor het hbo variëren de schattingen van de behoefte aan TZprofessionals op middellange termijn tussen de 2.550 (lage schatting) tot 7.020 (hoge schatting), voor het wo tussen de 1.650 (lage schatting) en 3.870 (hoge schatting).

\section{Vergelijking opleidingsaanbod met arbeidsmarkt}

Uitgaande van een vervangingsvraag van vier procent, zouden er (lage of hoge schatting) jaarlijks 100 tot 280 hbo-opgeleide en 65 tot 155 wo-opgeleide TZ-professionals moeten afstuderen om aan de behoefte op de arbeidsmarkt op (middel)lange termijn te voldoen (zie tabel 1). Met het huidige opleidingsaanbod binnen het hbo en wo kan aan die vervangingsvraag ruimschoots worden voldaan. In de

Tabel 1. Schatting van de arbeidsmarkt in 2020.

\begin{tabular}{|c|c|c|c|c|}
\hline $\begin{array}{l}\text { Opleidings- } \\
\text { niveau }\end{array}$ & $\begin{array}{l}\text { Huidige en korte } \\
\text { termijn arbeidsmarkt }\end{array}$ & Toename* & $\begin{array}{l}\text { Lange termijn } \\
\text { arbeidsmarkt }\end{array}$ & $\begin{array}{c}\text { Vervangings- } \\
\text { vraag** }^{* *}\end{array}$ \\
\hline \multirow[t]{2}{*}{ hbo } & Lage schatting: $\quad 425$ & $1,5 \times 2 \times 2=6$ & 2.550 & 100 \\
\hline & Hoge schatting: 1.170 & & 7.020 & 280 \\
\hline \multirow[t]{2}{*}{ wo } & Lage schatting: & & 1.650 & 65 \\
\hline & Hoge schatting: $\quad 645$ & & 3.870 & 155 \\
\hline
\end{tabular}

* Voor de schatting van de toename van de zorgvraag zijn de volgende rekenkundige aannames gebruikt: de zorgvraag neemt toe, waardoor de behoefte aan TZ-professionals ook toeneemt (factor 1.5); er is een verdergaande technologisering van de zorg (factor 2); er zijn overige ontwikkelingen, zoals taakherschikking, meer aandacht voor veiligheid, artsentekort, etc. (factor 2).

** Hierbij wordt ervan uitgegaan dat jaarlijks $4 \%$ nieuwe professionals in het arbeidsproces terecht moeten komen ter vervanging van professionals die met pensioen gaan of om andere redenen hun werk beëindigen. 


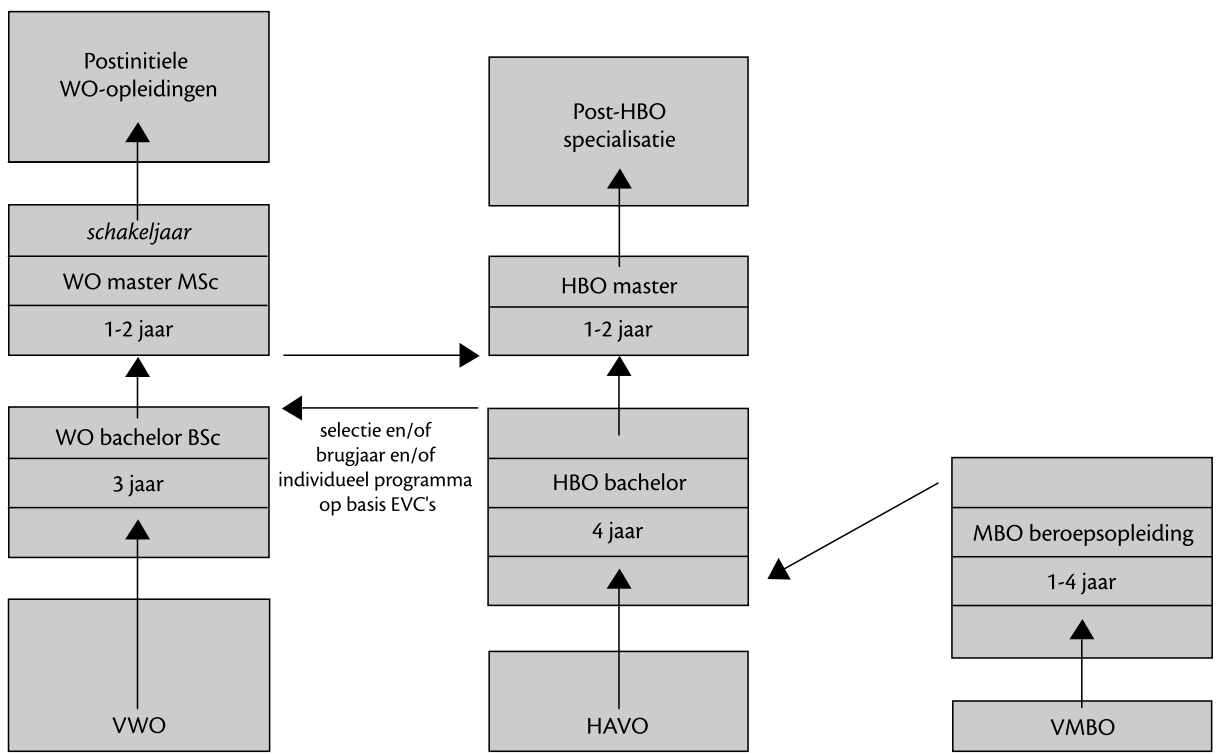

Figuur 2. Doorstroom tussen opleidingsniveaus (EVC, Erkenning van Verworven Competenties).

mbo-sector als geheel volstaat het aantal leerlingen voor de huidige vervangingsvraag.

\section{Hoe kan de kwaliteit van de}

\section{TZ-opleidingen gewaarborgd blijven?}

De commissie TZO noemt de volgende mogelijkheden om de kwaliteit van de TZopleidingen te verbeteren:

\section{Transparantie opleidingen}

Studenten en werkgevers hebben geen duidelijk beeld van de overeenkomsten en verschillen tussen de diverse TZ-opleidingen binnen hbo en wo, omdat coördinatie van de TZ-opleidingen vanuit het opleidingsveld ontbreekt. Daarnaast is het ook niet duidelijk voor welke beroepen en functies studenten opgeleid worden en wat het arbeidsperspectief is. Studenten moeten hiervan al voor hun studiekeuze een goed overzicht krijgen, zodat zij een bewuste keuze kunnen maken voor een bepaalde studie of voor een combinatie van studies. Dit bevordert de instroom en voorkomt uitval tijdens de opleiding. Voor werkgevers is het van belang te weten over welke competenties de opgeleide studenten beschikken.

\section{Aansluiting op beroepenveld}

Er is nog onvoldoende afstemming tussen de hbo- en wo-opleidingen en de werkgevers. Ook lijken deze instellingen zich er nog onvoldoende van bewust te zijn dat het beroepenveld aanzienlijk breder is dan alleen de intramurale zorg. Voor het bereiken en bedienen van de nieuwe, extramurale markt van bedrijven en particulieren voldoen de TZ-opleidingen in veel opzichten niet. Afstemming met extramurale werkgevers moet dan ook meer aandacht krijgen.

\section{Flexibel opleidingssysteem}

Om snel in te kunnen spelen op veranderingen in het TZ-beroepenveld is een flexibel opleidingssysteem nodig. Een opleidingssysteem waarbij studenten hun eigen opleidingsroute bepalen op basis 
van eigen voorkeuren, competenties en deficiënties en waarbinnen zij zonder al te veel moeite kunnen overstappen tussen verschillende opleidingsinstituten binnen en buiten Nederland. Binnen het hbo biedt het major/minor-model daarvoor de mogelijkheden en binnen het wo het bachelor/master-model. De mogelijkheden hiervan worden tot nu toe onvoldoende benut. Zo moet er meer duidelijkheid komen over de aansluiting tussen de eindtermen van de bachelorfase en de ingangseisen van de masterfase.

\section{Samenwerking tussen opleidingen}

Technologie en zorg zijn nog te veel gescheiden werelden. Dit leidt tot onbegrip over denk- en werkwijze van professionals in beide werelden, waardoor het benutten van elkaars kennis en kunde wordt bemoeilijkt. Het is noodzakelijk om bruggen te slaan tussen beide werelden. Ofschoon er enkele initiatieven in dit opzicht zijn, werken in het algemeen de zorgopleidingen en technologische opleidingen nog te weinig samen om daar verandering in te brengen.

\section{Verpleegkundige, medische en paramedi-} sche opleidingen

De huidige verpleegkundige, medische en paramedische opleidingen bereiden de studenten niet of nauwelijks voor op technologisering van de zorg en de communicatie daarover met TZ-professionals en patiënten. En dat terwijl zorgverleners steeds vaker samenwerken binnen multidisciplinaire teams. Verpleegkundige, medische en paramedische opleidingen moeten daarom in hun curricula hier meer aandacht aan besteden.

\section{Internationale oriëntatie}

De intramurale, en in mindere mate de extramurale, zorgtechnologie is internationaal georiënteerd. De TZ-opleidingen daarentegen zijn dat nog veel te weinig. De internationale oriëntatie van TZ-opleidingen moet worden bevorderd, bijvoorbeeld door het stimuleren van internationale uitwisseling tussen studenten en het aanbieden van een deel van het onderwijs in het Engels.

\section{Veiligheid}

Veiligheid van processen en apparatuur wordt steeds belangrijker door de toename van zorgtechnologie en de hogere eisen van patiënten en overheid. TZ-professionals gaan niet alleen in de zorg werken, maar ook in de nieuwe, kleine bedrijven die nog geen lange traditie op dat gebied hebben. De TZ-opleidingen moeten dan ook voldoende aandacht besteden aan de inschatting van veiligheidsrisico's en de maatregelen die nodig zijn om pro-actief het gewenste veiligheidsniveau te waarborgen.

\section{Conclusies en aanbevelingen}

\section{Behoefte aan TZ-professionals}

Zowel intra- als extramuraal zal de behoefte aan aanvullende medisch-technologische expertise op alle opleidingsniveaus toenemen. TZ-professionals zullen nieuwe kennis en vaardigheden inbrengen, taakdifferentiatie, substitutie en innovatie bevorderen en bruggen slaan tussen zorgverleners en technologen.

\section{Aantal studenten}

Binnen het mbo, hbo en wo zijn momenteel voldoende studenten in opleiding om aan de toenemende vraag naar TZ-professionals op korte en (middel)lange termijn te voldoen. De huidige TZ-opleidingen op hbo- en wo-niveau kunnen bovendien hun opleidingscapaciteit (aanzienlijk) vergroten als marktontwikkelingen daartoe aanleiding geven. 


\section{Instroom en doorstroom}

$\mathrm{Om}$ aan de toenemende vraag naar TZ-professionals te voldoen is het noodzakelijk dat het huidige aantal instromende studenten voor de nieuwe TZ-opleidingen en -afstudeerrichtingen binnen het hbo en wo op peil blijft. Belemmeringen voor een voldoende instroom en doorstroom moeten weggenomen worden. Daarvoor zijn de volgende acties nodig:

- De verschillen en overeenkomsten tussen TZ-opleidingen moeten transparant gemaakt worden.

- Voor studenten en werkgevers moet er een helder overzicht komen van de beroepen en beroepsprofielen en de bijbehorende competenties, waarop de diverse TZ-opleidingen voorbereiden.

- De doorstroom tussen de opleidingsniveaus moet bevorderd worden. Het bachelor/master-model biedt uitstekende mogelijkheden daartoe: universiteiten moeten zo snel mogelijk eindtermen van de bachelor- en masterprogramma's opstellen voor alle (TZ-)opleidingen die zij verzorgen. Daarnaast is het noodzakelijk dat zij de instroomvereisten voor de masterfase definiëren (zie figuur 1). Voorts zullen universiteiten, hogescholen en overheid moeten aangeven of, en zo ja hoe, doorstroom vanuit een hbo-bachelor naar een universitaire master binnen hetzelfde aandachtsgebied mogelijk wordt (zie figuur 2).

- De bekendheid van de TZ-opleidingen moet vergroot worden om voldoende studenten te (blijven) interesseren voor de nieuwe TZ-opleidingen in wo en hbo.

\section{Starten nieuwe opleidingen}

De commissie is van mening dat terughoudend moet worden omgegaan met het starten van nieuwe TZ-opleidingen. Het is efficiënter en flexibeler om bestaande op- leidingen aan te passen dan een nieuwe opleiding te starten. Bij teruglopende belangstelling kan een nieuwe afstudeervariant binnen een bestaande opleiding zonder veel problemen weer worden afgebouwd. Het bachelor/master-model biedt bovendien uitstekende mogelijkheden voor het inbouwen van minors in de bachelorfase en het combineren van zorg- en techniekmodules.

\section{Opleidingsduur}

Iedere TZ-opleiding binnen het wo kan bestaan uit drie jaar bachelor (breed), een of twee jaar master (verdieping en specialisatie), gevolgd door een eventuele postinitiële opleiding, zoals klinische fysica. De commissie is geen voorstander van een opleidingsduur langer dan vijf jaar.

\section{6. $80 \%$ techniek - $20 \%$ zorg}

Een TZ-professional moet zoveel mogelijk additionele kennis inbrengen in een team. Dit impliceert dat de TZ-professional in de zorg vooral technologische kennis toe moet voegen. Voor de commissie betekent dit dat zij tijdens de opleiding een brede en diepgaande kennis over technologie verwerven. Daarnaast maakt de student een keuze voor één of enkele aandachtsgebieden binnen de zorg. Het is noodzakelijk dat studenten door middel van een minor en/of ruime stages binnen zorginstellingen inzicht verwerven in de organisatie en cultuur van de zorg. Daarbij moet de nadruk liggen op het leren communiceren met zorgverleners (artsen, verpleegkundigen, paramedici). De commissie vindt dan ook dat de TZ-opleidingen ongeveer $80 \%$ technologische en $20 \%$ medische kennis en vaardigheden aan moeten bieden.

\section{Internationale oriëntatie en veiligheid}

TZ-opleidingen moeten zich meer internationaal oriënteren. Ook moeten zij 
ruim aandacht besteden aan veiligheid van apparatuur en processen.

\section{Platform voor gebruikers en producen- ten}

Het is van groot belang dat de TZ-industrie producten levert die aansluiten op de behoeften van patiënten en cliënten. Daartoe is het noodzakelijk dat ervaringen van patiënten en cliënten in de intraen extramurale zorg op gestructureerde wijze kunnen worden teruggekoppeld naar de producenten. Hiervoor moet een gebruikersplatform worden opgericht.

\section{TZ-kenniscentrum voor hbo en wo}

Voor hbo en wo moet een TZ-kenniscentrum opgericht worden waarin opleiders en arbeidsmarkt met elkaar overleggen, zodat de TZ-opleidingen zich tijdig kunnen aanpassen aan de veranderende marktvraag.

\section{Samenwerking opleidingen}

Zorgopleidingen en technologische opleidingen moeten beter en meer met elkaar samenwerken om de kloof tussen zorg en techniek te overbruggen. De HBO-Raad heeft het initiatief daartoe al genomen.

\section{Verpleegkundige, medische en para- medische opleidingen}

Verpleegkundige, medische en paramedische opleidingen moeten meer aandacht besteden aan de technologisering van de zorg. Voor zorgprofessionals met een afgeronde opleiding is bij- en nascholing op dit gebied nodig.

\section{Communicatie in de zorgopleidingen}

TZ-opleidingen, medische, paramedische en verpleegkundige opleidingen moeten in hun curriculum meer aandacht besteden aan communicatie- en samenwerkingsvaardigheden tussen TZ-professionals en zorgprofessionals. Het is van belang dat zorgprofessionals en TZ-professionals inzicht krijgen in de denkwijze en potentiële bijdrage van professionals met een andere achtergrond.

\section{Juridische positie TZ-professional}

De commissie acht aanvullende regelgeving en het inrichten van eventuele beroepsregisters voor nieuwe TZ-professionals niet gewenst. De Wet Beroepen Individuele Gezondheidszorg (WBIG) biedt voldoende houvast om nieuwe TZprofessionals een plek te geven in een professioneel (behandel)team.

\section{De auteurs:}

Prof. dr. T. Sminia is rector magnificus van de Vrije Universiteit te Amsterdam en was voorzitter van de commissie Technologie, Zorg en Opleiding.

Drs. F.B.M. Sanders is radioloog in het Diakonessenhuis te Utrecht en voorzitter van de Raad voor de Volksgezondheid en Zorg (RVZ).

Dr. A.W. de Weerd is neuroloog/klinisch neurofysioloog bij de Stichting Epilepsie Instellingen Nederland (SEIN) te Zwolle.

Prof. dr. ir. P.A. Wieringa is hoogleraar Mens-Machine Systemen aan de Technische Universiteit Delft, afdeling BioMechanical Engineering.

Drs. D.C. Duchatteau, MBA is vennoot bij LSJ Medisch Projectbureau te Leiden.

Drs. L.J. Schmit Jongbloed, MBA is arts en vennoot bij LSJ Medisch Projectbureau te Leiden.

Drs. M.C.Willemsen is communicatieadviseur/tekstschrijver, met als specialisatie beleidscommunicatie in de gezondheidszorg, en directeur van MC Communicatie te Nieuwerkerk a/d IJssel.

Dr. J.C.C. Borleffs is internist en directeur opleidingen van het Onderwijsinstituut van het UMC Utrecht.

Correspondentieadres:

Prof. dr. T. Sminia, Vrije Universiteit, de Boelestraat 1105, 1081 HV Amsterdam,wel.kuipers@dienst.vu.nl. 


\section{Summary}

Introduction: There is a growing demand for professionals with combined expertise in technology and health care (technology and care (TC) professionals) both intramurally and extramurally. Colleges of higher education and universities have launched new technology and care education courses (TC programmes).

Method: A commission, set up by the Minister of Health, Welfare and Sports, has estimated the medium term (2020) need for TC professionals with different levels of training. This estimate was compared with the number of students enrolled in the new TC curricula.

Results: The new TC curricula have enough capacity to meet the expected demand for TC professionals. Moreover, training capacity can easily be increased, should the need arise. The core competence of TC professionals comprises a broad and in-depth knowledge of technology. In this way the TC professional brings added value to the health care team.

Conclusion and main recommendations: Although the demand for TC expertise is growing, the current number of students in TC education courses is expected to be sufficient to meet the expected medium term requirements. TC professionals will have a major role to play as bridge builders between the separate worlds of technology and health care. TC curricula should give prominence to technology and in addition offer training in communication skills and supply students with adequate knowledge about health care and its organisation and culture. The commission envisages curricular content that consists for $89 \%$ of technology and for $20 \%$ of medical knowledge and skills. In order to promote TC as an attractive option for students, the commission advises schools and employers to provide students with good information about the differences and similarities between the various TC courses and degrees, good information about function profiles for TC professionals and good opportunities for moving from one course and educational level to another. (Sminia T, Sanders FBM, De Weerd AW, Wieringa PA, Duchatteau DC, Schmit Jongbloed LJ, Willemsen MC, Borleffs JCC. Technology with care. Quantity and quality in the education of experts in technology and health care. (Dutch Journal of Medical Education 2005;24(1):35-43.) 